\title{
Orthodontics and oral mucosal lesions in children and teenagers
}

\author{
L. Sicard ${ }^{1}$, L. Benmoussa ${ }^{2}$, N. Moreau ${ }^{3}$, B. Salmon ${ }^{3}$, A.-L. Ejeil ${ }^{3}$ \\ 1 DESCO \\ $2 \mathrm{AHU}$ \\ ${ }^{3} \mathrm{MCU}-\mathrm{PH}$ \\ Oral Medicine Department of Bretonneau Hospital, Paris \\ Our gratitude to the Orthodontic Department for providing the iconography for this article
}

SUMMARY

Children and teenagers with orthodontics may be affected by infectious, hereditary, traumatic, malignant, or idiopathic oral mucosa lesions. Orthodontists have to be able to detect, identify, and treat effectively or to address the patient to a specialist. Here we discuss this difference to make their diagnosis and management easier for the practitioner.

\section{KEY WORDS}

Oral mucosa, orthodontics, oral appliances, oral lesions

\section{INTRODUCTION}

The estimated prevalence of oral mucosal lesions is $8 \%-60 \%$ in the general population ${ }^{1,8,17,2}$. In children and adolescents, it increases with age. The causes can be infectious, hereditary, malignant, idiopathic, or iatrogenic in nature. The four main lesions found are canker sores, traumatic lesions, herpes, and lingual lesions ${ }^{5,20,13,9}$. In addition, certain systemic pathologies (inflammatory diseases of the coIon and intestines, IBD, hemopathies, and diabetes) may also have oral manifestations ${ }^{5}$.

The presence of intraoral material during orthodontic treatment is associated with a greater risk of traumatic or reactive lesions $^{18}$. These are either treatment-induced or of allergic origin.

The diagnosis of oral mucosal pathologies is based on a rigorous approach including a thorough anamnesis, clinical examination with the search for elementary lesions, and additional examinations. Through regular check-up appointments during orthodontic treatment, the practitioner is able to detect the appearance of lesions, to monitor their evolution, and to manage them if necessary.

Address for correspondence:

Ludovic Sicard - Bretonneau Hospital, Department of Oral Medicine

- 23 rue Joseph de Maistre - 75018 Paris

E-mail: ludovic.sicard@aphp.fr

Article received: 16-10-2017. Accepted for publication: 25-12-2017.

This is an Open Access article distributed under the terms of the Creative Commons Attribution License (http://creativecommons.org/licenses/by/4.0), which permits unrestricted use, distribution, and reproduction in any medium, provided the original work is properly cited. 


\section{ELEMENTARY LESIONS AND DIAGNOSTIC APPROACH}

The elementary lesion (Table I) is used to guide the diagnosis by comparing it with a nosological group. Its description must include its borders, texture, color (erythematous, keratotic, and pigmented), suppleness or induration, and number of lesions (whether single or multiple).

The diagnostic approach is based on the patient's medical history and clinical examination. It leads to one or more diagnostic hypotheses or even a positive diagnosis.

Obtaining the diagnosis may require additional tests, such as biopsy and/or excision, biological assessment, serology, and imaging ${ }^{15}$.

The medical history is of particular interest to children and their parents. It examines the history of the condition, its date of onset, and the type and appearance of the lesion. The condition may be accompanied by symptoms or early signs. Its discovery may be fortuitous or be mentioned by the patient due to discomfort or pain. The lesion's development can be continuous or via intermittent flare-ups, or even constitute a recurrence. Family history, ethnic origins, lifestyle habits, and medications (antiseptics in mouthwash, ointments, and antibiotics) can help guide the diagnosis. A particular area, such as current conditions or a systemic disease, can be the cause of oral lesions (IBD or hemopathies in particular).

The clinical examination must meet a strict methodology and must systematically provide information on various points ${ }^{16}$.

The extraoral examination begins with examining the appearance of

\section{Table I: Primary elementary lesions ${ }^{7}$}

\begin{tabular}{|c|c|c|}
\hline Elementary lesion & Size & Description \\
\hline Macule & $<5 \mathrm{~mm}$ & \multirow{2}{*}{$\begin{array}{l}\text { Not indurated, circumscribed, consisting of a color change of the mucosa without relief or } \\
\text { hollow (spot). Erythematous (example: acute myeloid leukemia) or pigmented (example: } \\
\text { idiopathic macular melanoma). }\end{array}$} \\
\hline Range & $>5 \mathrm{~mm}$ & \\
\hline Papula & $<5 \mathrm{~mm}$ & \multirow{2}{*}{$\begin{array}{l}\text { In relief, firm, non-liquid, protruding, circumscribed, palpable. Increased epithelio-conjunctival } \\
\text { volume. Red, white, or pigmented. The plaque may result from the confluence of several } \\
\text { papules. }\end{array}$} \\
\hline Plaque & $>5 \mathrm{~mm}$ & \\
\hline Nodule & & $\begin{array}{l}\text { Firm, non-protruding, round or oval, deep (of the chorion), sometimes painful, linked to } \\
\text { inflammatory or tumoral (benign or malignant) involvement. Generally large. Keratotic, } \\
\text { erythematous, or pigmented. }\end{array}$ \\
\hline Vegetation & & $\begin{array}{l}\text { Hypertrophic or hyperplastic circumscribed epithelio-conjunctival proliferation consisting of } \\
\text { growths (cauliflower appearance). Of variable morphology (filiform or lobulated appearanc- } \\
\text { es). Pediculated or sessile. Usually refers to papillomas, warts, and condylomas. }\end{array}$ \\
\hline Vesicule & $<5 \mathrm{~mm}$ & $\begin{array}{l}\text { Elevated circumscribed intraepithelial elevation with serous or hemorrhagic fluid content. } \\
\text { The thin roof is quickly eliminated in the mouth, giving way to erosion (secondary lesion). }\end{array}$ \\
\hline Bubble & $>5 \mathrm{~mm}$ & $\begin{array}{l}\text { Clear, yellowish, or hemorrhagic fluid collection. Fragile roof that breaks easily (formation of a } \\
\text { secondary erosive lesion or post-bullous ulcerative lesion). May be intra- or subepithelial. }\end{array}$ \\
\hline Pustule & $<5 \mathrm{~mm}$ & Vesicle that contains pus. A vesicle can turn into a pustule due to bacterial contamination. \\
\hline Erosion & & $\begin{array}{l}\text { Loss of superficial substance (epithelial involvement without involvement of the chorion). } \\
\text { Heals without leaving a scar. Most often secondary to a vesicle or an intraepithelial bubble } \\
\text { after the rupture of its roof. Surface most often erythematous. }\end{array}$ \\
\hline Ulceration & & $\begin{array}{l}\text { Loss of epithelial and conjunctive tissue. Leaves a fibrinous layer by exudation after removal } \\
\text { of the basal membrane. More painful than erosion. Usually heals in about } 10 \text { days, some- } \\
\text { times with cicatricial sequelae. Most common causes are canker sores, trauma, subepitheli- } \\
\text { al bubbles, and carcinomas. }\end{array}$ \\
\hline
\end{tabular}


Table 2: Types of additional examinations

\begin{tabular}{|l|l|}
\hline Additional examinations & Examples of indication \\
\hline Complete blood count & Recurrent ulcerations, testing for anemia, or hemopathy \\
\hline Fasting blood glucose, HbA1c & Diabetes control \\
\hline Vitamin assessment (B9, B12 ...) & Canker sores with macrocytic anemia \\
\hline Ultrasound & Salivary gland tumor \\
\hline Magnetic resonance imaging & Assessment of bone/soft tissue tumor \\
\hline Serology & HSV1 or HSV2 testing for atypical primary herpes infection \\
\hline Biopsy & Histological confirmation of the diagnostic hypothesis \\
\hline Mycological examination & Mycosis resistant to first-line treatment \\
\hline
\end{tabular}

integuments (skin and skin- associated structures, such as nails, hair, and dander) and mucocutaneous diseases that can be associated with oral manifestations. This is followed by palpation for lymphadenopathy and salivary glands and the search for any swelling or facial asymmetry.

The extraoral examination is thorough. The practitioner spreads the cheeks, explores the vestibular and lingual floor, while holding the tongue in place with a compress. They look carefully at the lesion, describe the clinical aspect (color, texture, induration, and boundaries) and topography (location and size). The lesion may be homogeneous (one type of primary lesion) or heterogeneous (multiple primary lesions at the same site). The palpation evaluates the consistency and reveals any possible induration. For red lesions, the vitropressure test makes it possible to establish if the lesion is of capillary origin or not. If the lesion turns white, it indicates a vascular origin.

The initial lesion can frequently and rapidly undergo changes due to certain elements of the oral environment (humidity, variable $\mathrm{pH}$, dental microtrauma, food, hygiene, and occurrence of superinfections).

These observations are recorded on a diagram of the oral mucosa as well as images of the lesion. These documents are attached to the medical file to monitor the evolution of the condition.

Additional tests are ordered when there is still doubt about the diagnosis. They are guided by the diagnostic hypotheses and are not systematic (Table II).

\section{MUCOSAL PATHOLOGIES RELATED TO ORTHODONTIC TREATMENTS}

Mucosal pathologies related to orthodontic treatment have three major causes: traumatic, infectious, or reactive.

Traumatic pathologies take different forms depending on severity. They vary according to the type of orthodontic appliance. Brackets are associated with the presence of erosion or keratosis caused by friction on the corresponding mucous membranes. Arches are often associated with wound ulcers by piercing the mucosa facing them ${ }^{18}$. Mini-screws are frequently associated with erythema and erosions ${ }^{19}$. After 
removal, they create cicatricial sequelae in $>40 \%$ of cases $^{21}$.

The definitive diagnosis of a traumatic injury is only made when the lesion disappears after elimination of the suspected cause.

with regular and light friction. It is clinically translated by a homogeneous white plate.

Traumatic ulceration (Fig. 2) is painful; it results from the aggression and iatrogenicity of a piece of orthodontic equipment or the head of a mini-screw (the placement of composite on the head of the mini-screw can minimize this risk). ${ }^{12}$

Located next to the causal element, it Keratosis (Fig. 1) is a defensive reaction of the mucosa in the face of aggression.

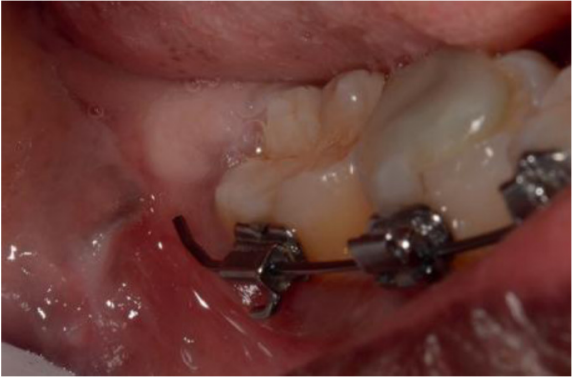

Figure 1

Reactive jugal keratosis opposite the end of a Ni-Ti arch.

It settles in reaction heals in 10-15 days after elimination of the cause.

Sometimes, the healing process is painful and botryomycoma can be observed (Fig. 3).



a

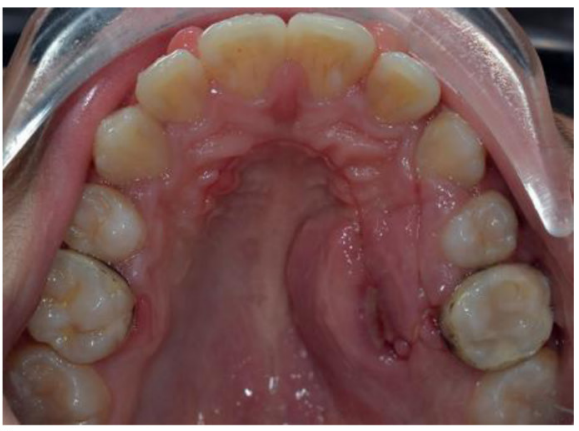

b

Figure 2

Left palatal ulcer in relation to a quad-helix and a brace on 26.

a) Device in place. b) Traumatic ulceration.

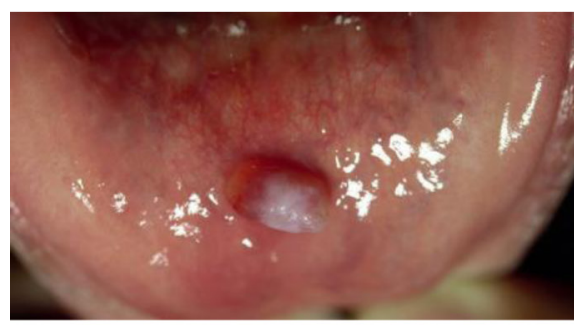

a

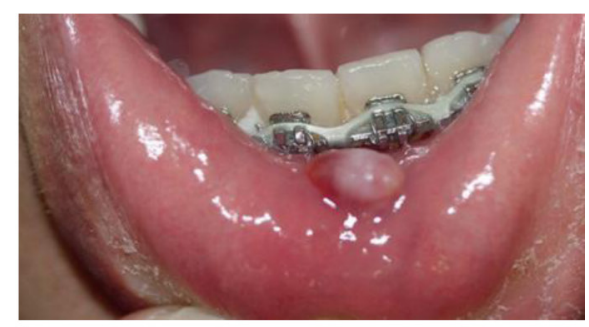

b

Figure 3

a) Botryomycosis of the lower lip with reactive keratosis.

b) Position of the lesion opposite orthodontic brackets. 
Necrosis represents the extreme stage of the traumatic lesion. A case using a Nance arch has been reported in the literature ${ }^{11}$.

Epulis and mucoid cysts are less common lesions.

Epulis (Fig. 4) is a benign inflammatory tumor of the gingiva and develops in response to a local chronic irritative factor (brackets, tartar, and interdental spaces). Clinically, epulis appears as a localized nodule appearing on the marginal gingiva or alveolar processes. Inflammatory epulis is most common following orthodontic treatment. Its size can be significant. Highly vascularized, it bleeds easily. Its treatment is based on excision up to the bone contact, removal of the causal factor if possible, and oral hygiene reeducation. In children, the presence of an inflammatory epulis requires a $\mathrm{CBC}$ to rule out leukemia.

The mucoid cyst (Fig. 5) is a pseudocyst, often of traumatic origin, resulting from the extravasation of saliva after the rupture of the excretory canal. It develops mainly in the accessory salivary glands and particularly on the lower lip and the floor of the mouth. It takes the form of a

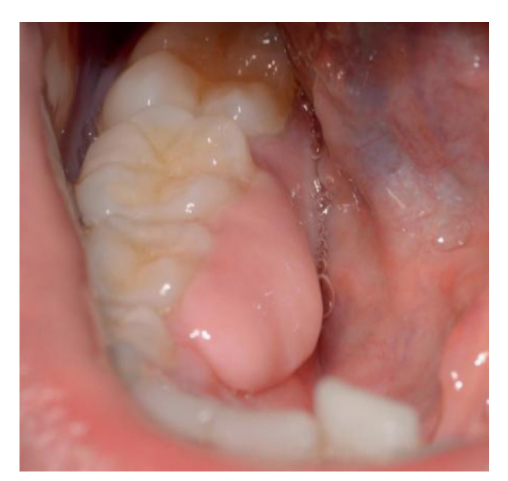

Figure 4

Fibrous epulis, pediculated, related to a local irritant factor between 45 and 46 . painless translucent or bluish collection, is hemispherical, and ranges in size from a few millimeters to a few centimeters in diameter. Treatment is through excision. On the oral floor, it is called a ranula or a "little frog" colloquially (Fig. 6).

Infectious diseases are favored by dental congestion and the presence of exogenous material, which constitute a bacterial retentive factor. The most common is gingivitis (Fig. 7). It is treated with proper oral hygiene, complicated by the presence of the multi-attachment device. Parental involvement and child empowerment are fundamental, as well as the demonstration and use of adapted hygiene equipment.

Mycotic infections are very rare, with the main causative agent being Candida albicans. C. albicans is present in

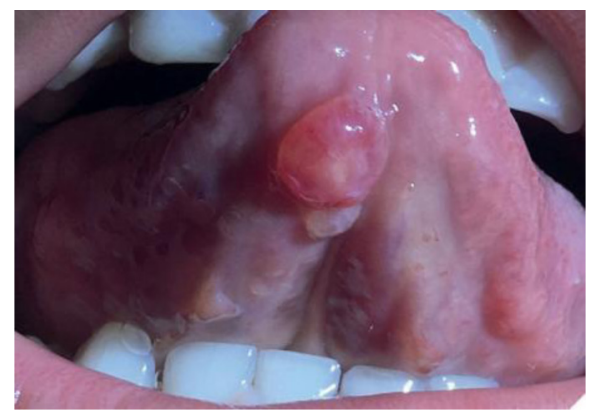

Figure 5

Mucoid cyst on the ventral side of the tongue.



Figure 6

Ranula on the oral floor. 




Figure 7

Gingivitis after removal of the orthodontic appliance.

the oral flora of $>30 \%$ of the population and its concentration increases in the presence of removable resin devic$\mathrm{es}^{6}$. Its presence in the mouth is not enough for it to become pathogenic (candidiasis). The main risk factors in children are long-term use of antibiotics or a background of immunosuppression/ depression. Clinically, acute mycosis (or thrush) manifests as diffuse erythematous stomatitis of the mucous membranes. Whitish granulations converge to form slightly fluffy white layers, which are more or less extensive and detach easily on scraping to give way to an erythematous mucous membrane (or even bleeding). When these layers are very extensive, they form a pseudo-membrane.


Figure $8 a$ and $b$

Hyperplasia and sagittal erythema in relation to a palatal plate.
Without treatment, candidiasis evolves, either toward spontaneous cure if the aggravating factors are eliminated or toward chronicity and possibly digestive dissemination.

Angular cheilitis is a particular form of candidiasis. It is characterized by angular cheilitis with bilateral involvement of the labial commissures on the cutaneous and mucous slopes. It is affected by salivary flow and maceration in the commissural folds and maintained via a licking behavioral tic.

The diagnosis of candidiasis is clinical.

Treatment involves the elimination of aggravating factors and a local treatment with amphotericin $B$ (Fungizone $\AA$ ) as a first-line defense (oral suspension, 2 spoonfuls in mouthwash 5 times a day for 3 weeks; take the mouthwash then swallow to prevent digestive dissemination).

Mycological testing is reserved for ambiguous or treatment-resistant forms.

Reactive pathologies include hyperplasia, diapneusias, canker sores, non-viral papillomas, ${ }^{4}$ and allergies.

Hyperplasias occur in the context of chronic irritation created by multi-attachment devices or palatal plates (Figs. 8, 9 and 10). Localized around the irritative cause, they take the form 



Figure 9

a) Hyperplasia around the head of a mini-screw. b) Aggravation of hyperplasia after placement of the elastic.

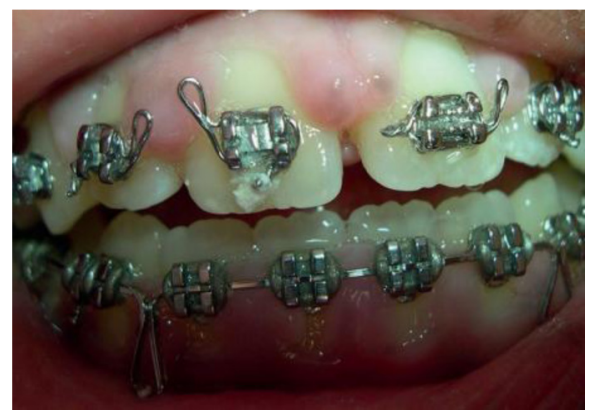

Figure 10

Hypertrophic reactive papillae.

of an increase in tissue volume, are firm and covered with a healthy, erythematous, or keratotic mucosa.

Diapneusia (Fig. 11) is indirectly linked to orthodontic appliances via the spaces they create. Frequently, it presents as an asymptomatic nodule and is generally $<1 \mathrm{~cm}$ in diameter. It can be located on the cheeks, lips, and tongue and is caused by excessive suction (wide interdental space). Treatment consists of the removal of the lesion's root. Relapses may be avoided if the cause is corrected.

Cases of nickel allergy are reported during orthodontic treatment (use of $\mathrm{Ni}$-Ti arches). This allergy affects approximately $19 \%$ of the general population ${ }^{7}$ and

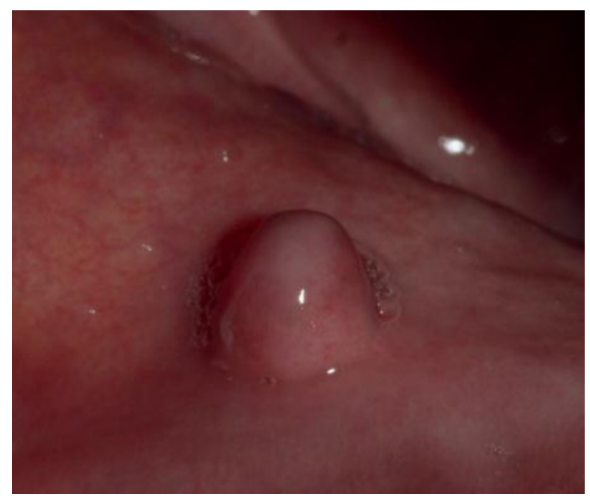

Figure 11

Diapneusia of the mucosal side of the lower right lip following a suction tic.

corresponds to a delayed cell-mediated hypersensitivity (type IV of the Gell and Coombs classification).

It occurs in two phases: a sensitization and an expression phase. Clinically, 2-3 days after the second exposure, it manifests as contact dermatitis or edema. Reactions at the mucosal level are rare because the nickel is coated with a salivary film, the alloy is of better quality than that of a piercing, and the mucosa presents fewer antigen presenting cells than on the skin. In addition, the oral medium may induce nickel tolerance ${ }^{3}$. 


\section{MUCOSAL PATHOLOGIES NOT RELATED TO ORTHODONTIC TREATMENT}

Many of them are more common in children and adolescents.

Lesions related to dental trauma are usually found in patients with a pronounced overlapping Angle Class II. The lesion is located on the palate opposite the free edge of the mandibular incisors (Fig. 12).

Primary herpes infection (Fig. 13) corresponds to a patient's first contact with the herpes simplex virus 1 (HSV1). It usually affects children before the age of 10 . Preceded by fever and oropharyngeal pain, vesicules appear in the oral mucosa. They lead to erosions that produce acute gingivostomatitis. Peri-oral cutaneous involvement may be present. These erosions can converge to create large painful erosive expanses with polycyclic contours.

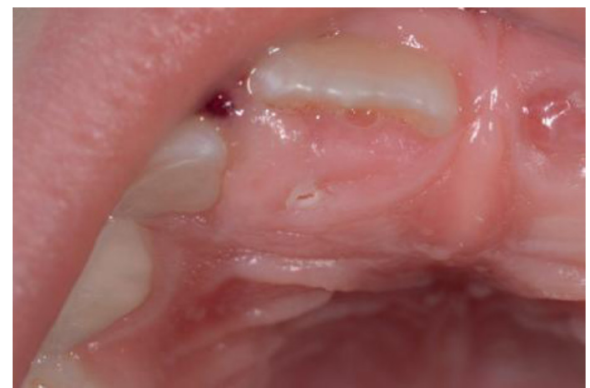

Figure 12

Traumatic lesion of the palate in relation to a Class II division 1, with ulceration of traumatic origin in relation to the occlusion.

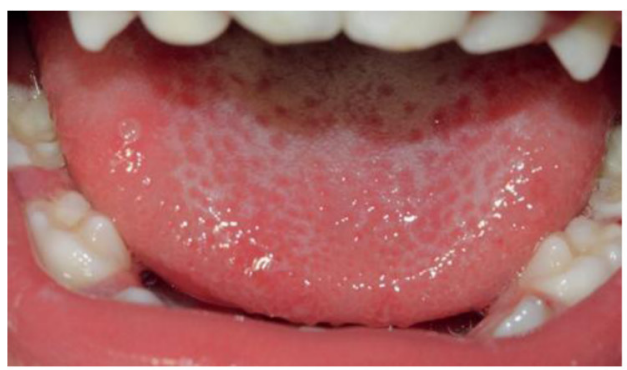

a



b



C

Figure 13

Primary herpes infection. a) Erythematous tongue with cyclic erosion at the right edge. b) Gingivitis and left jugal erosion. c) Extraoral view with herpetic vesicule on the lower lip. 
Accompanying signs are general state alteration (GSA), severe dysphagia, hypersialorrhea, and frequent cervical lymphadenopathies. Bacterial superinfection can occur due to the impossibility of brushing due to pain. Healing occurs in 2 weeks without sequelae. During this period, the patient is contagious through direct contact with infected secretions (saliva).

The first contact with the HSV usually goes unnoticed. Symptoms are triggered in only $10 \%$ of cases.

Differential diagnoses include other viral pediatric diseases: herpangina; hand, foot, and mouth disease; and chicken pox. Others that should also be considered are infectious mononucleosis, bacterial angina, oral aphthosis in its miliary form (without GSA oradenopathy), rarely erythema multiforme, or drug toxicity.

The treatment of a primary herpes infection is based on a symptomatic component (analgesic, antiseptic, and antibiotic) and an etiological component (antiviral in the replicative phase, acyclovir type, systemically).

After healing, the virus remains latent in the body. Herpes labialis is the most classic clinical form of recurrence, but this recurrence may occur in the oral mucosa, more frequently in the palate compared with the first molars.

Treatment of recurrences is based on an antiviral (acyclovir) topically applied up to 5 times daily for 4-5 days (should be started at the prodromal level) and local antiseptics (chlorhexidine).

Chicken pox and shingles (Fig. 14) are diseases caused by varicella zoster virus (VZV) (HHV-3 group). Chicken pox is the primary infection.

Its diagnosis is clinical. It is characterized by fever and skin rash (transient or fleeting) followed by a moderate fever with characteristic vesicular and pruritic rash (dewdrop on healthy skin), polyadenopathy, and oral enanthema (generalized erythematous stomatitis with vesicle formation giving way to painful circular or oval superficial erosions). Healing takes 10 days without sequelae.

Treatment of chickenpox is symptomatic and is based on analgesics (NSAIDs are contraindicated).

Shingles is the clinical expression of the resurgence of $V Z V$, with unilateral eruptions following a nerve pathway. It mainly affects adults and occasionally teenagers.

Hand, foot, and mouth disease (Fig. 15), caused by a virus (coxsackie virus A16), particularly affects young children aged $<5$ years, usually as an epidemic in spring and summer. Clinically, it results in an enanthema beginning with bright red macules $2-8 \mathrm{~mm}$ in diameter, evolving toward grayish vesicles, surrounded by an erythematous halo in a moderate influenza context. Diagnosis is based on the simultaneous presence of cutaneous elements in the fingers and toes (palmoplantar lesions). Healing is spontaneous and occurs within 2 weeks without sequelae.

Measles, also caused by the virus Morbillivirus, usually affects pre-school children who have not yet been vaccinated. The invasion phase is manifested by oculo-respiratory catarrh with high fever, digestive symptoms, and Köplik sign. Almost pathognomonic but fleeting, Köplik sign is characterized by bluish and keratotic papules on the inside of the cheeks, often facing the first molar. The condition phase corresponds to a morbilliform exanthema (maculopapular rash) with a healthy 


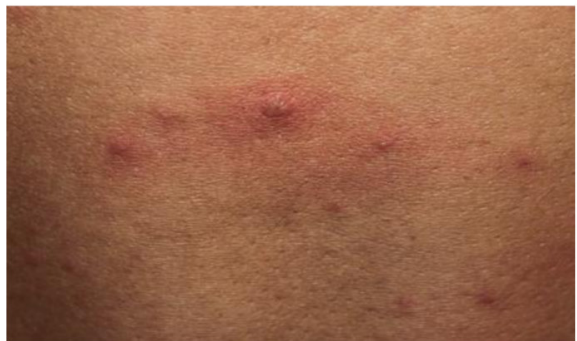

a



C



b

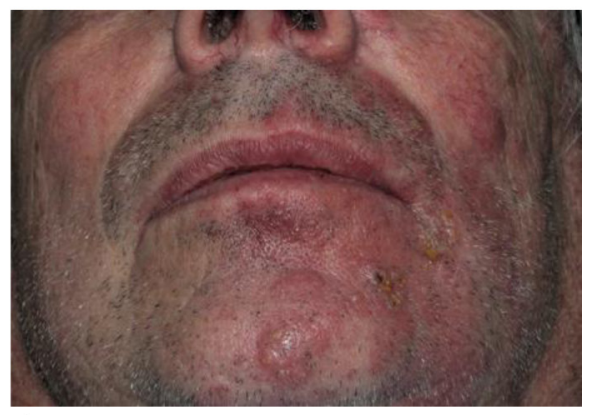

d

Figure 14

a) and b) Chicken pox in a young adult with a cutaneous vesicle on the left and lingual erosions on the right.

c) and d) V3 area shingles, intraoral view on the left and extraoral on the right.



a

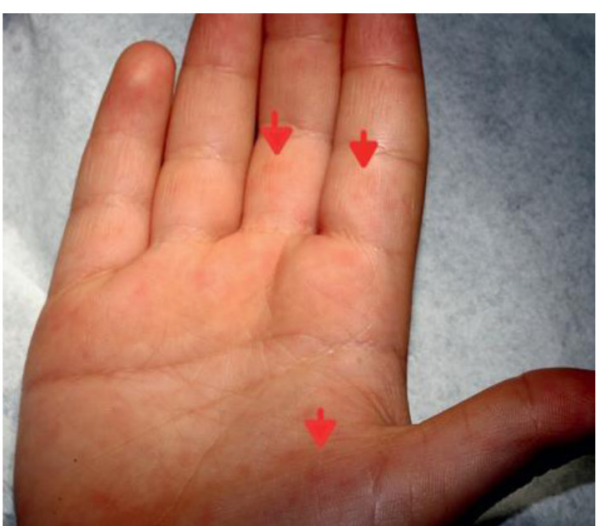

b

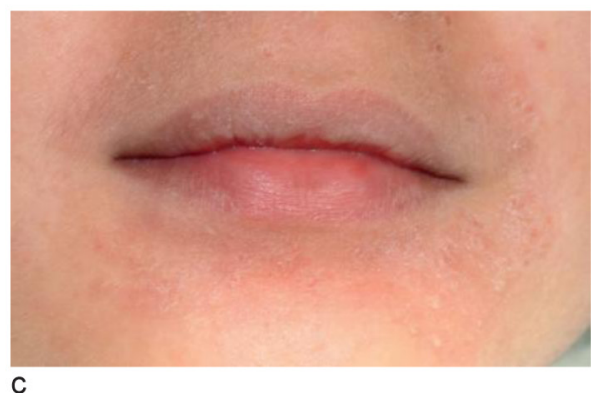

C

Figure 15

Hand, foot, and mouth disease. a) and b) Enathema on the right foot and the right hand.

c) Grayish vesicles and peri-oral erythematous halos. 
skin interval between the elements. Treatment is symptomatic and relies on analgesics and antibiotic therapy in case of superinfection. Vaccination remains the best preventive treatment. Due to insufficient immunization coverage, measles is resurging in Europe and should not be ignored in adolescents and young adults due to the severe complications it causes.

Herpangina is a vesicular pharyngitis of viral etiology (coxsackievirus A4) and particularly affects children. It results in fever accompanied by dysphagia followed by ulcerated lesions located on the veil of the palate and its anterior pillars It affects the tonsils and tongue. Spontaneous evolution is favorable in a few days.

White sponge nevus (or Cannon's spongy white nevi) is a hereditary dyskeratosis localized preferentially to the jugal mucosa, which takes on a white-gray, slightly wrinkled appearance, similar to an opalescent veil. The mucosa remains supple. These white spots, slightly raised, are detached by scratching in the form of scales, revealing an intact submucosa underneath.

The palatal and gingival mucosa, which do not have a submucosa, are almost always unaffected. The lesion occurs less frequently in other mucous membranes of the aerodigestive tract or the genital system. The differential diagnosis is white lesions of the oral mucosa.

Oropharyngeal canker sores (Fig. 16) are painful ulcerations of the mucosa, with rounded regular margins, surrounded by an erythematous inflammatory halo. These lesions are common and affect up to $50 \%$ of the population. Three types of canker sores are distinguished according to their size:

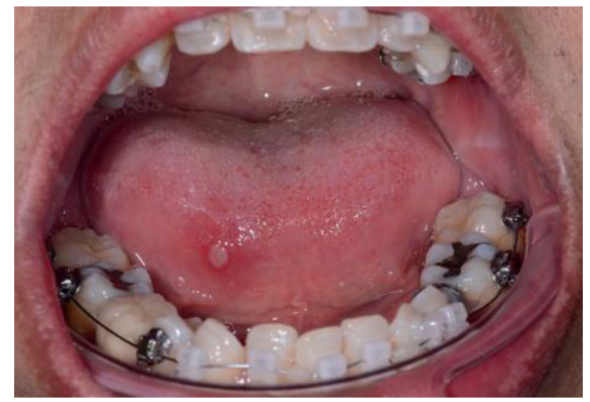

Figure 16

Canker sore on the tip of the tongue with fibrinous border and erythematous halo.

common canker sore $(<1 \mathrm{~cm})$, giant canker sore $(>1 \mathrm{~cm})$, and miliary aphtosis $(1 \mathrm{~mm})$. While most are idiopathic in origin, some causes should not be overlooked $^{10}$ such as IBD, Behçet's disease, neutropenia, anemia, and/or vitamin deficiency. The treatment of common canker sores is symptomatic. The literature does not indicate a direct relationship between orthodontic treatment and canker sores.

Malignant pathologies, which are fortunately very rare in children, are the second leading cause of death in this age group after accidents. With the exception of leukemia and lymphoma, children with cancer appear to be in good health. A peculiarity of these pathologies in children is their rapid progression. Any swelling without an infectious portal of entry, especially in the maxillary or mandibular regions, should evoke this diagnosis.

Acute lymphoblastic leukemia (ALL) affects children more than adults. Accompanied by an alteration in the patient's general health status, it is visible in the mouth in the form of purpura and gingivorragia.

More generally, hemopathies can result in diffuse or localized gingival 
hypertrophies, often bluish-red in color, which bleed at the slightest trauma. Hypertrophy results from the infiltration of tissues by leukemic cells. The clinical picture is that of fatigue accom- panied by fever and lymphadenopathy, skin paleness (anemia), infections (neutropenia), and hemorrhagic syndromes (thrombocytopenia). Neutropenia can result in mouth ulcers.

\section{CONCLUSION}

Oral mucosal pathologies encountered by the orthodontist are often benign and acute. Treatment-related lesions are mostly reactive and require correction of causal factors, improvement of oral hygiene, and/ or mucosal protection. Pathologies not associated with treatment are most often viral and clinically manifest as vesicles. The adage says that a child who falls ill quickly will get better quickly. The persistence of lesions or deterioration of the child's general condition necessitates their referral to a specialized department for further examinations in search of an underlying general pathology.

\section{BIBLIOGRAPHY}

1. Amadori F, Bardellini E, Conti G, Majorana A. Oral mucosal lesions in teenagers: a cross-sectional study. Ital J Pediatr 2017;43(1):50.

2. Baricevic M, Mravak-Stipetic M, Majstrorovic M, Baranovic M, Baricevic D, Loncar B. Oral mucosal lesions during orthodontic treatment. Int J Paediatr Dent 2011;21(2):96-102.

3. Benmoussa L, Ejeil AL. Additional examinations for oral cavity pathologies: when are they required? Rev Odonto Stomatol 2017;46:4-11.

4. Bessa CF, Santos PJ, Aguiar MC, do Carmo MA. Prevalence of oral mucosal alterations in children from 0 to 12 years old. J Oral Pathol Med 2004;33(1):17-22.

5. Castellanos JL, Díaz-Guzmán L. Lesions of the oral mucosa: an epidemiological study of 23785 Mexican patients. Oral Surg Oral Med Oral Pathol Oral Radiol Endod 2008;105(1): 79-85.

6. Dridi SM, Ejeil AL. L'examen clinique des muqueuses buccales. Rev Odonto Stomatol 2008;37.

7. Dridi SM, Ejeil A, Gaultier F, Meyer J. La gencive pathologique de l'enfant à l'adulte. Diagnostics et thérapeutiques. Espace ID.

8. Dridi M, Ejeil AL, Vi-Fane B, Godeau G. Papillome buccal : présentation d'un cas clinique. Rev Odonto Stomatol 2004:33:111-117.

9. Garcia-Pola Vallejo MJ, Martinez Diaz-Canel Al, Garcia Martin JM, Gonzalez Garcia M. Risk factors for oral soft tissue lesions in an adult Spanish population. Community Dent Oral Epidemiol 2002;30(4):277-285.

10. Gölz L, Papageorgiou SN, Jäger A. Nickel hypersen- sitivity and orthodontic treatment: a systematic review and meta-analysis. Contact Dermatitis 2015;73(1):1-14. 
11. Gölz L. et al. Differences in human gingival and dermal fibroblasts may contribute to oral-induced tolerance against nickel. J Allergy Clin Immunol 2016;138(4):1202-1205.e3.

12. Hibino K, Wong RWK, Hägg U, Samaranayake LP. The effects of orthodontic appliances on Candida in the human mouth. Int J Paediatr Dent 2009;19(5):301-308.

13. Jung S, Choi YJ, Lee D-W, Kim K-H, Chung CJ. Cross- sectional evaluation of the prevalence and factors associated with soft tissue scarring after the removal of miniscrews. Angle Orthod 2015;85(3):420-426.

14. Kleinman DV, Swango PA, Pindborg JJ. Epidemiology of oral mucosal lesions in United States schoolchil- dren: 1986-87. Community Dent Oral Epidemiol 1994;22(4):243-253.

15. Kovac-Kavcic M, Skaleric U. The prevalence of oral mucosal lesions in a population in Ljubljana, Slovenia. J Oral Pathol Med 2000;29(7):331-335.

16. Majorana A, Bardellini E, Flocchini P, Amadori F, Conti G, Campus G. Oral mucosal lesions in children from 0 to 12 years old: ten years' experience. Oral Surg Oral Med Oral Pathol Oral Radiol Endod 2010;110(1):e13-e18.

17. Marquezan M, de Freitas AOA, Nojima LI. Miniscrew covering: an alternative to prevent traumatic lesions. Am J Orthod Dentofac Orthop 2012;141(2):242-244.

18. Mehrotra, R. et al. Prevalence of oral soft tissue lesions in Vidisha. BMC Res. Notes 2010;3:23.

19. Stephan Aphtose buccale récidivante | Pas à Pas en Pédiatrie. Available at: http:// pap-pediatrie.fr/immu-no-infectio-parasito/aphtose-buccale-recidivante. (Accessed: 16th October 2017).

20. Sullivan ZC, Harrison JE. Tissue necrosis under a Nance palatal arch: a case report. J Orthod 2017;1-5.

21. Wang Z, Zhang D, Liu Y, Zhao Z. Buccal mucosal lesions caused by the interradicular miniscrew: A preliminary report. Int J Oral Maxillofac Implants 2010;25(6):1183-1188. 